\title{
MOSTRA COMEMORATIVA DOS 70 ANOS DE INSERÇÃO DA ESCOLA DE ENFERMAGEMANNA NERY NO CENÁRIO UNIVERSTÁRIO (1937 - 2007)
}

Commemorative Exhibition of the 70 Years of Insertion of the

Anna Nery School of Nursing in the University Scenery (1937 - 2007)

Muestra Conmemorativa de los 70 Años de Inserción de la Escuela de Enfermería Anna Nery en el Escenario Universitario (1937 - 2007)

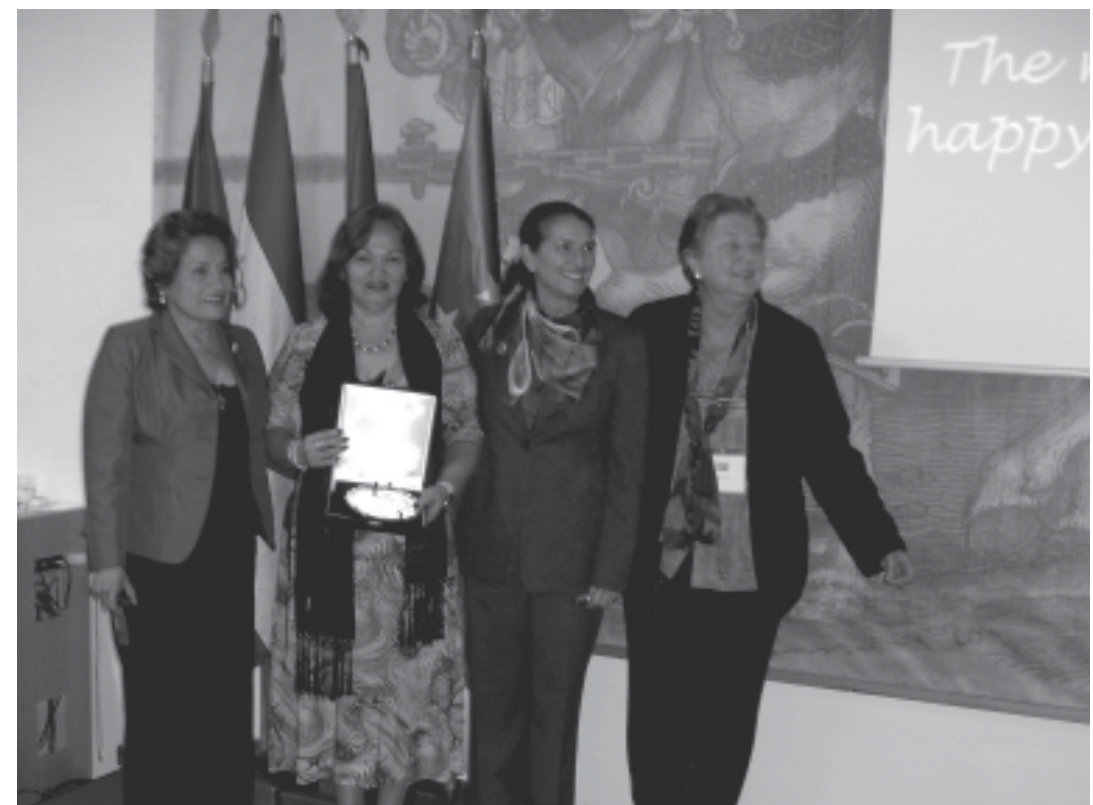

Cerimônia de Outorga do Prêmio Susana Espino Muñoz à Profa . Dra . Maria Antonieta Rubio Tyrrell durante a IX Conferência Iberolatinoamericana, promovida pela ALADEFE/UDUAL, em Toledo, Universidade de Castilla, La Mancha - Espanha (2007)

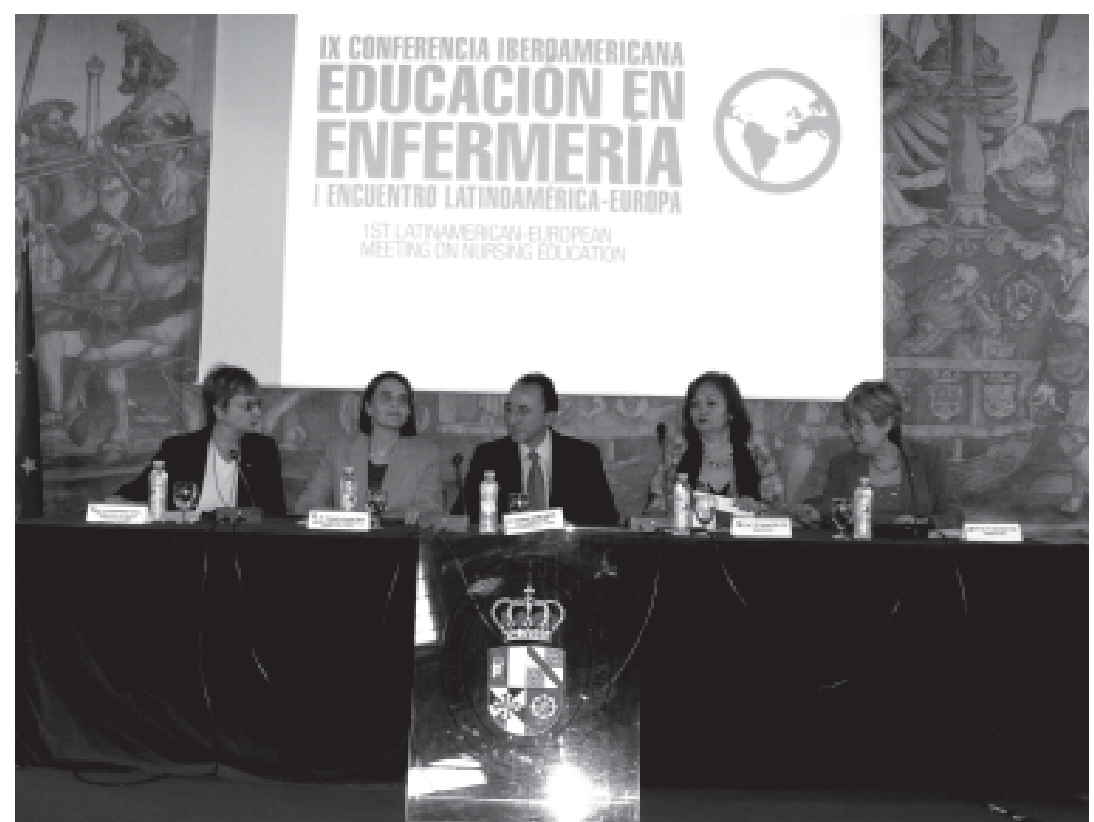

Cerimônia de Posse da Presidência da ALADEF - IX Conferência Iberolatinoamericana, promovida pela ALADEFE/UDUAL, em Toledo, Universidade de Castilla, La Mancha - Espanha (2007) 


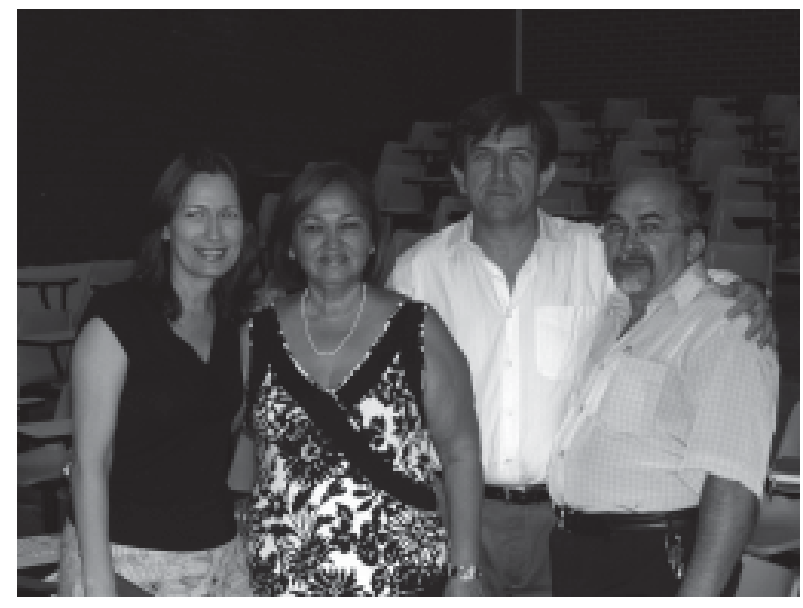

Cerimonial Comemorativo do Dia da Obstetriz - Brasília - DF (2007)

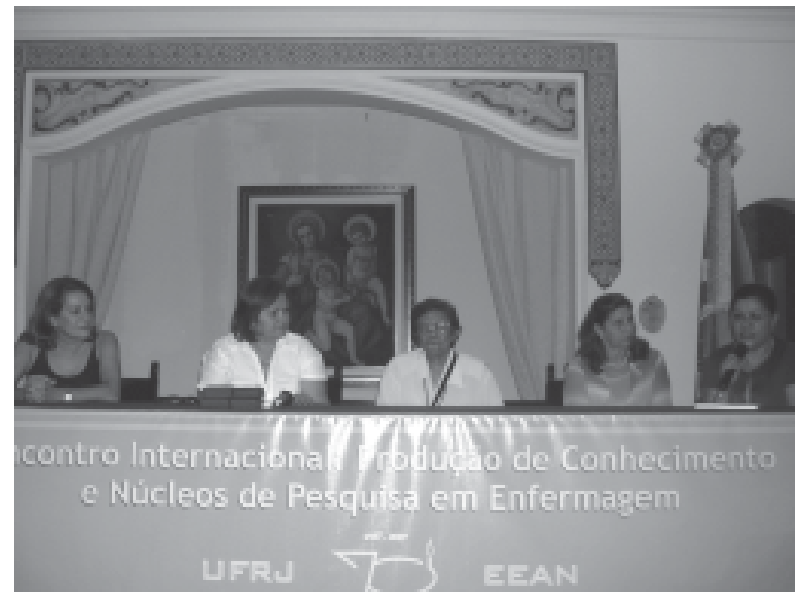

Encontro Internacional: Produção de Conhecimento e Núcleos de Pesquisa em Enfermagem - Centro de Convenções do Hotel Glória Rio de Janeiro - RJ (2007)
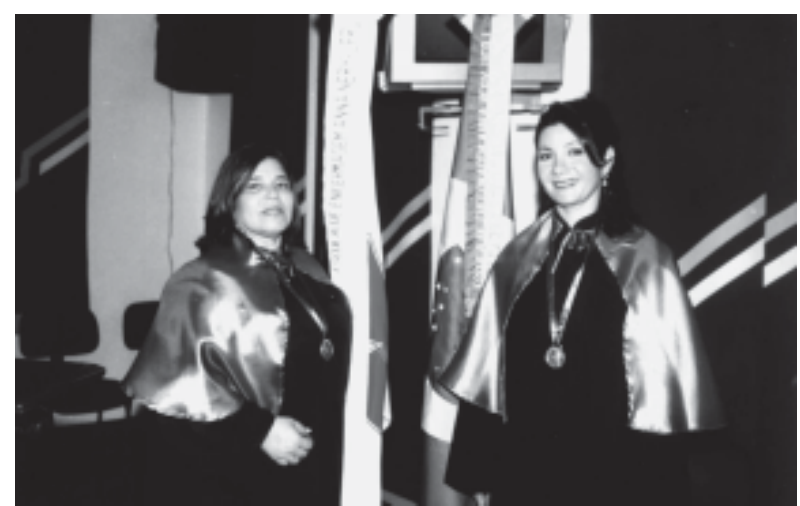

Cerimônia de Intronização das Professoras Títulares Dra Márcia Assunção Ferreira e Dr ${ }^{a}$ Ligia de Oliveira Viana Pavilhão de Aulas da EEAN/UFRJ (2007)

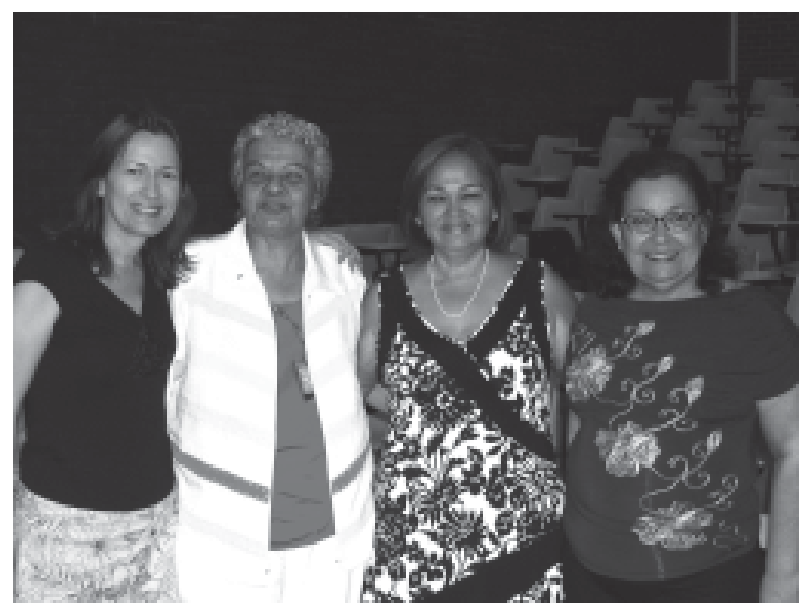

Cerimonial Comemorativo do Dia da Obstetriz - Brasília - DF (2007)

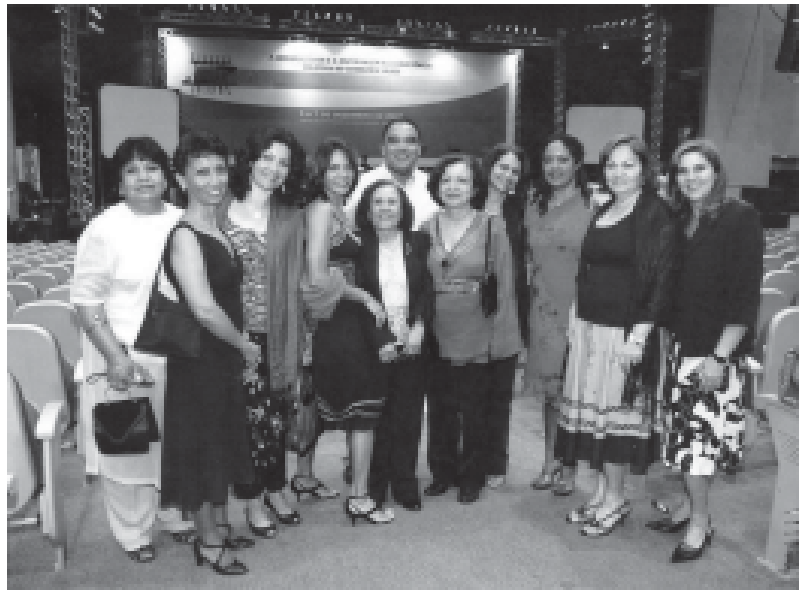

Participação da EEAN/UFRJ NO 59 CBEn - Brasília - DF (2007)

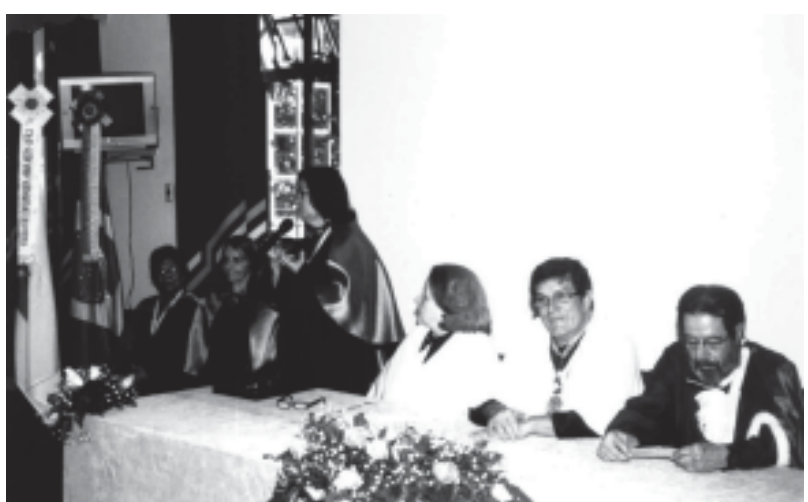

Cerimônia de Intronização das Professoras Títulares $\mathrm{Dr}^{\mathrm{a}}$. Márcia Assunção Ferreira e Dr ${ }^{\mathrm{a}}$ Ligia de Oliveira Viana Pavilhão de Aulas da EEAN/UFRJ (2007) 